\title{
DETERMINANTS OF LOAN REPAYMENT USING DATA MINING TECHNIQUES
}

\author{
Abbas Heiat, Montana State University-Billings, USA \\ Rakesh Sah, Montana State University Billings, USA
}

dx.doi.org/10.18374/JIFS-13-3.12

\begin{abstract}
This research uses data mining techniques to identify the factors that are relevant to determining loan repayments using data from over 1,200 small loans that were granted for a variety of purposes for the period 2006 to 2011 by a regional bank located in the United States of America. We use quarterly data to identify loans that were in default, and IBM SPSS modeler data mining software to isolate factors that seem to influence loan default.
\end{abstract}

Keywords: Data Mining, Loan default, Microloan Repayment. 